\title{
Inhalt
}

Vorwort - V

Einleitung -1

I Person und Werk im kulturellen Gedächtnis der Jahrhunderte: Spuren und Konturen

Anna Schreurs-Morét

Ariosts Gesichter in Deutschland - Inszenierungen eines Dichters - 15

Emma Louise Brucklacher

Ariost-Viten in Deutschland - 43

Carolin Hahn

Ariost-Reminiszenzen in deutschen Italienreisen von der Frühen Neuzeit bis ins zwanzigste Jahrhundert - 68

Achim Hölter

Ariost in Dichterbibliotheken der Goethezeit — 91

Wilhelm Kühlmann

Dichtergedichte und Dichterstimmen zu Ariost im 19. Jahrhundert — 116

\section{Translatorische Konkurrenzen}

Astrid Dröse

Ariost im Journal - Friedrich August Clemens Werthes' Übersetzung des Orlando Furioso in Wielands Teutschem Merkur (1774) - 147

Gabriella Catalano

August Wilhelm Schlegel und Ariost: Übersetzung als kritisches

Experiment -166 


\section{Peter Kofler}

Die Furioso-Übersetzung von Johann Diederich Gries: Höhepunkt und Aporie der deutschen Ariost-Rezeption — 181

\section{Francesco Rossi}

Deutsche Übertragungen von Ariosts Satiren im 18. Jahrhundert 197

\section{Intertextuelle Referenzen}

\section{Achim Aurnhammer}

Die produktive Aneignung Ariosts in Deutschland zwischen Humanismus und Barock. Mit einem Ausblick auf Moscherosch und

Grimmelshausen - 217

Dieter Martin

Wielands Ariost -256

Mario Zanucchi

Die ariostesken Kleinepen des Ludwig Heinrich von Nicolay — 273

Achim Aurnhammer

Goethes Ariost -291

Alexander Nebrig

Heine mit Ariost an den König. Die ästhetische Vermittlung politischer Autorschaft im Versepos Atta Troll (1843) — 316

Ritchie Robertson

Ariost aus Schweizer Sicht, 1854-1909: Keller, Burckhardt, Meyer, Spitteler und Widmann -337

Gloria Colombo

Ariost in der klassischen Moderne: Spuren in Hofmannsthals Werk

Franziska Merklin

Peterchens Mondfahrt (1912) als Orlando Furioso für Kinder — 377 
Ralph Häfner

Das Puppenspiel Orlando und Angelica (1912): Traditionsgeschichtliche Aspekte des Burlesken im Werk von Erich Klossowski und Julius Meier-Graefe -390

Manfred Pfister

Becketts Anspiel: Der Orlando Furioso als Theater des Absurden -422

\section{Musikalische, bildkünstlerische und architektonische Adaptationen}

Alfred Noe

Ariost-Rezeption in der Wiener Hofoper - 437

Wolfgang Hirschmann

So fern, so nah: Händels Ariost-Opern in der aktuellen

Inszenierungspraxis $-\mathbf{4 5 8}$

Silke Leopold

Was vom Epos übrig blieb: Ariost-Opern von Hasse und Haydn — 476

Michael Niedermeier

Der Rasende Roland im ,Gartenreich': Die Askanier, die Abstammung und die Macht der Leidenschaften $-\mathbf{5 0 1}$

Lorenz Enderlein

„Christliches Epos“ und profane Historienmalerei: Julius Schnorrs Bilder zum Orlando Furioso - 535

Doris Strack

Hübners Roland: Die ikonographische Tradition (Orlando nella grotta dei malandrini, XIII 37) 581

Birgitta Coers

Ironie und Wahnsinn: Arnold Böcklins Ariost-Paraphrasen — 603

Register -625 
